\title{
Research of Chinese Traditional Medical Ethics
}

\author{
Jing Jiang, Zhengdao Zhou, Li Zhang
}

Jiangxi medical college, Shangrao, Jiangxi, 334000

\author{
Keywords: Traditional Ethics, Medical Value, Chinese Efficient
}

\begin{abstract}
Chinese traditional ethical culture plays an important role in the traditional ideology and culture of the Chinese nation. Chinese traditional culture is an ethical culture. Due to the differences between the natural environment and people's way of life, the ancient Chinese came from the brutal civilization into a path different from that of Western Europe. China is in the absence of a complete destruction of clan blood relationship from brutal to civilization, so that clan organizations in China long retained. This is the special path of the country by the clan, the home for the country's foundation, the country for the expansion of the home. This kind of family-based social structure makes an ethical and moral significance in the construction of social order. Chinese traditional culture has always attached importance to ethics, "University" opened that "the way of the university, in the Mingde, in the people, in the only good." Chinese history of the philosophers of no one regardless of moral ethics, self-cultivation of a family of a country to become the world's intellectuals of the practice of the way. Chinese traditional ethical culture mainly refers to the traditional ethical culture of Confucianism, Taoism, Buddhism and so on from the pre-Qin to the Revolution of 1911, among which Confucian ethical culture is its core content.
\end{abstract}

\section{Introduction}

The traditional Chinese ethical culture, which is rooted in the history of the Chinese nation, not only has the unique content adapted to this nation, but also has the unique thinking and theoretical characteristics of this nation. The traditional ethical culture of China has the following three characteristics: one is the ethical view of the Taoism, Taoism and nature. Ethical relations as one of the basic elements of socialization, I pointed out that between people and all things, between people and society have a strong relationship between the natural. I think that the origin of life is the way, and from the philosophy of the objective vision, demonstrated the "life of a life, two students, three students three things" Laozi twenty chapter ". Man is one of all things. Therefore, the road is the origin of all things, the mother of the world. Advocate the relationship between man and man to obey the world, to the law of heaven and earth, Road law naturally, and then proposed by the days of justice, poly gas gas, abstinence to harm, not to hurt the yin and yang, clean and despicable, indiscriminate ethical interpersonal norms. According to the law put forward as interpersonal etiquette and advocating this etiquette. Second, there is a social and political ethical tendencies of the relationship between the criminals and the patriarchal clan. In China, as early as two thousand years ago in the Spring and Autumn and Warring States period, there is a "human", "moral" concept. "Lun" refers to the relationship between people, Confucianism has put forward the most important relationship between people and five, namely, "five lun" monarch, father and son, couple, brother, friend, this five-lun relationship is Blood and patriarchal relations, and by the feudal social system to be cured. Now in our country's ethical life is still everywhere to see their traces of thought. "Reason" refers to the truth and the rules. "Ethics" is to deal with the relationship between people should follow the principles and rules. The concept of "ethics" was first seen in our country, "Book of Rites", which points out that "musicians and virtues are also".

\section{The Main Essence of Chinese Traditional Medical Ethics}

China is a long history of ancient civilization, thousands of years in China's history of the 
development of medicine, a group of people who love the people of the common people, not only the development of Chinese medicine, and created a unique medical ethics system, the formation of ancient China The tradition of medical ethics. Traditional medicine of the motherland attaches great importance to medical ethics, the generation of doctors to Germany as a career, the conduct of the country. Chinese medicine contains a wealth of medical content, in the motherland medical books, are common to see the medical ethics.

Under the influence of the Confucian ideology of benevolence, the traditional Chinese medical ethics put forward the "medicine is benevolence", that medicine is love, treatment of life skills, medicine is the world, to save the suffering of mankind science. Medical is benevolence first stressed that love to save people. Confucius said: "benevolent love". China's first theoretical theory of Chinese medicine, "Huang Di Nei Jing" put forward: "heaven and earth cover, all things are prepared, Mo Gui people", asked to use medical "Ji group students." Zhang Zhongjing in the "Treatise on the miscellaneous disease" in that order, he "feel the past, the loss of death, save the death of the Mo save, is the ground for the old training, Bocaizhongfang", as is the "love people know", " "The life of the great physician Sun Simiao also stressed:" life is heavy, you have a daughter, one side of the economy, Germany more than this, in order to keep the health of the child, ", Ask the doctor" Zhi Cun relief "," vowed to save the spirit of the panic "(" Prepared to pay the daughter of the big doctor ").

Medical is benevolent third emphasis on the superb medical life to save people. Traditional medical ethics that the doctor to achieve love to save the people of the world desire, we must have superb medicine, and superb medical access, must have an open mind, study hard. Gong Tingxian in the "rejuvenation recorded," said, "Xu Shi-fu's" ancient and modern medical system, "pointed out:" medicine of the living, learn not fine, anti-death " Sun Simiao also believes that medicine is profound and profound, "to fine to micro" knowledge, "so scholars must Boji doctor source, Jingqin tireless, not hearsay, in terms of medicine has been, since the self-mistaken" (" "). In the history of Chinese medicine development also emerged many medical scientists, such as Zhang Zhongjing, Sun Simiao, Li Shizhen, etc., they diligently seek old training, fine study of art, to superb medicine, to achieve love to save people, sincere love of the lofty aspirations.

Traditional medical ethics that the doctor to deal with the relationship between patients to inject a strong emotion, the sickness of the sick can put themselves in place, pushing people and people, so as to empathy, deep sympathy. Sun Simiao said: "If the disease to seek help, ... the same as the same, like the pro-thought of ... see his troubles, if any, deep sadness, ... its suffering from devastating diarrhea, foul can not look, People are bad people, but made shameful miserable worry about the meaning, could not afford to read the heart of a mustard "(" big doctor sincere "). Yuan Dynasty Zhu Danxi diagnosis and treatment of patients, "Although the rain on the road, not so far," and educate his disciples "patient engraved as old, and desire to Yiya?" Between the lines filled with compassion and deep feelings. Ming Dynasty physician Li Tiancheng said: "I am in the people who, if the mother of my mother." Qing Dynasty famous Fei Bo Xiong also said: "I have a disease, hope how to save the doctor how? My parents and his wife have a disease, see the doctor of the rescue how?" So "easy to look and benefit from the light carry on. Benefit from the light is the conscience is now, fearless heart. "(" Medical essence "). Push themselves and people, empathy, put themselves in the ground for the sake of the patient, so that patients will be deeply sympathetic, sincere care, engaged in medical work with conscience, highly responsible, it will not seek personal gain and damage the interests of patients. This is just as the Qing Dynasty famous Yu Chang said: "Health, benevolence also." Gentleman gentleman must Benedict, Benedict love, then as people still ask, ask their bitter, since the place.

\section{The Modern Value of Chinese Traditional Medical Ethics}

Market economy to stimulate people's sense of interest, some medical staff to practice as a means of profit, only re-pay regardless of duties and obligations, reduce the quality of medical services, raise the price of medical services, not proficiency in medicine, and strive to improve the technical level, The work done too, too, because the reason did not establish a correct view of the 
profession and values. Inherit and carry forward the traditional medical ethics to save the professional concept, help to help medical workers to correctly understand the medical profession of the purpose and basic tasks, clear their duties and obligations, to arouse love and sense of responsibility, establish a healthy career, Sense of honor, to enhance career aspirations. So as to enhance the professionalism and sense of responsibility of medical workers, to promote the medical staff to consciously follow the professional ethics, research and innovation, continuous search, and strive to improve the quality of medical services to join the medical profession Career, to save the suffering of mankind for the lofty ideals, to fulfill the treatment of life, save the dying of the sacred duty, and strive to lift the suffering of patients, promote medical care and medical science continue to develop.

At present, by the impact of market economy and medical science and technology, the relationship between physician and patient physiology and commercialization, the lack of trust between doctors and patients, medical disputes continue to increase. How to change the status quo of the relationship between doctors and patients, build a good and harmonious relationship between doctors and patients, has become an important issue of great concern. China's traditional medical ethics emphasizes the "Benedict" situation of suffering, can be used as an effective way to improve the relationship between modern doctors and patients. The tension between modern doctors and patients and the lack of trust between doctors and patients, there is an important reason is that some medical staff to suffer emotional indifference. Medical work is the object of thinking, emotional and suffering from the suffering of the disease patients, engaged in medical work, not only to rely on technology, but also need medical staff into the deep feelings. Medical practitioners to learn the ancient physician "Benedict" situation of attitude and "easy to land and view" of the waiting consciousness, in the medical and even more into the sincere feelings, often empathy, more than the patient point of view, Listen carefully to the patient's complaints, put themselves in place to understand the feelings of patients, will be able to feel the same, caring sympathy for the pain of patients, deep sympathy for the patient's experience, enhance the sense of responsibility, desalination of desires, real emergency patients, Every effort to help patients relieve the suffering of the disease. This will be able to change the situation of emotional indifference between doctors and patients to strengthen communication between doctors and patients to increase mutual trust, so that the relationship between doctors and patients to re-close and harmonious.

At present, in the market economy conditions, the impact of money worship is also the impact of the sacred medical field. Some of the hospital one-sided pursuit of economic benefits, increase the economic burden of patients; some medical staff by the principle of interest-driven, do not work in the life-saving duties, the pursuit of additional income, medical advice, to the patient acceptance, ask for "red envelope" Large prescription, engage in excessive medical care, not from the benefit of the patient's health interests, but focus on their own personal income, rebates, seriously affected the hospital and medical workers reputation and image, corrupt medical ethics, intensified Tension between doctors and patients.

Learning and carrying forward the traditional medical ethics emphasized by the righteousness and benefit of the concept of justice, to help medical workers keep in mind the fundamental purpose of medical work, the relationship between justice and justice, clean medical style has important practical significance. The particularity of medical work requires medical workers to always put the patient's life and health interests in the first place, and always save the treatment as a motive and purpose. If the profit will be used as the purpose of practicing medicine, then many things will harm the patient will appear, medicine will lose its nature and the negative side of the study, the doctor will not be the benefit of human white angel, and will become " "Therefore, the traditional medical ethics has always stressed that medical workers to love to save people in the first place, not to concentrate on medical care by the property, but to do the heart of relief. With the development of the times and the deepening of knowledge, we also need to affirm the rationality of medical workers to pursue the legitimate interests of individuals in order to reflect the technical value of their work and the risk of medical services provided. However, the medical interests of improper interests, the profit is built on the interests of patients harmed, and the responsibility to save the side of the 
wounded, heavy and light meaning, even unscrupulous behavior is immoral, is the need to contain The The ancients once said: the first meaning and then profit, first profit and then righteous disgrace. Zhu Xi said more clearly: "is the righteousness is free, the road is their own merits, specifically to care about the interests, may not be beneficial, may not be active" ("Zhuzi language" volume thirty-seven). Because of this, Xu Dachun that: "fame from the date of the natural demand for the public, and benefit also followed. If the merit, the fame and fortune, doctors who suffer and dance" ("medical source theory"). Therefore, inheritance and learn from the traditional medical ethics righteousness, justice to benefit the values, education, medical workers to save the lives of the first place, clean practice, to save lives and work to pay and contribute to the pursuit of personal interests, consciously resist money worship And the medical field of unhealthy wind invasion, re-tree medical workers a good reputation and image, is the current medical ethics construction of important content.

\section{Conclusion}

In our discussion of the impact of traditional ethical culture on Chinese doctors, it is necessary to see that the ethics of Chinese medicine is at the earliest stage of its development from the simple humanitarianism, which is roughly the same as that of ancient Greece and Egypt. After the Tang Dynasty, because Confucianism became the dominant thought of society at that time, it permeated all aspects of social life, which inevitably affected the formation and development of doctor's ethics. Many of the medical views and principles of traditional Chinese medicine are actually reflected in the field of medicine and medical practice, which is the embodiment of Confucian Confucianism in medical and medical practice. This is an important way compared with western medical ethics. difference.

\section{References}

[1] Wu Mengchao. The medical weight in Germany and Germany Tak Tak innovation [J]. Chinese Medical Ethics. 2006 (02)

[2] Pan Xinli. Medical research is a new study [J]. Chinese Journal of Medical Ethics. 2005 (04)

[3] Sun Zhigang. Using the traditional Chinese medicine virtues to strengthen the construction of modern medical ethics [J]. Chinese Journal of Medical Ethics. 2004 (04)

[4] Jin Shuqin, Liu Weibin, Bai Xia, Zhang Jihong, Wen Duanxu. Traditional Chinese Medicine ethics tradition characteristics and influence [J]. Modern Journal of Integrated Traditional and Western Medicine 1999 (11)

[5] Zhang Daqing, Cheng Zhipan. Medical is benevolence: Chinese medicine professional ethics of the basic principles [J]. Medicine and philosophy. 1999 (06)

[6] Qiu Hongzhong. Confucian view of justice and its practice [J]. Chinese Journal of Medical Ethics. 1996 (04) 